\title{
Attribution of Biochemical Characters in Downy Mildew Resistant and Susceptible Hybrids of Pearl Millet
}

\author{
Pooja Sangwan, Kushal Raj*, L.K. Chugh, Annu and Annie Khanna \\ Department of Plant Pathology, CCS Haryana Agricultural University, Hisar \\ Pin 125004 (Haryana), India \\ *Corresponding author
}

\section{Keywords \\ Downy mildew, Pearl millet, \\ Peroxidase, Catalase, Phenol, Flavanol, Total chlorophyll}

Article Info

Accepted: 18 April 2018 Available Online: 10 May 2018
A B S T R A C T

Downy mildew, caused by Sclerospora graminicola (Sacc.) Schroet, is a disease of great economic significance in the production of pearl millet (Pennisetum glaucum). Host physiology particularly host metabolites and oxidising enzymes get disturbed due to attack of Sclerospora graminicola. Altered state of oxidative enzyme plays an important role in plant metabolism during pathogenesis. In the present investigation biochemical characterization of pearl millet genotypes - HHB 223 and $7042 \mathrm{~S}$ was carried out at 30, 40, 50 and 70 DAS. Total phenols were higher in resistant genotype at 30 DAS in comparison to susceptible genotype but with the progression of disease total phenols decreased in resistant genotype at 40,50 and 70 DAS but in susceptible genotype they increased. Orthodihydroxy phenol was higher in resistant genotype at all the stages in comparison to susceptible genotype. Flavanols were higher in resistant genotypes at 30 DAS in comparison to susceptible genotype. With the progression of the disease, flavanol content decreased in both the genotypes but more reduction was observed from 30 DAS to 70 DAS in susceptible genotype. Total chlorophyll and carotenoid content decreased with the progression of systemic infection in both resistant and susceptible genotypes. Total soluble sugars were higher in resistant genotype in comparison to susceptible genotype. Peroxidase and catalase activities were higher in susceptible genotype at early stages of growth but at later stages higher in resistant genotype. Polyphenol oxidase did not show any significant difference in resistant and susceptible genotype. Phenylalanine Ammonia Lyase activity was higher and continuously increased in susceptible genotype at all stages of growth whereas Tyrosine Ammonia Lyase activity was found in traces in both the genotypes. Protein content was initially higher in susceptible genotype at 30 DAS and 40 DAS but it decreased with disease progression. Change in the activities of antioxidant enzymes and in various metabolites can be used as a biochemical marker for the degree of resistance.

\section{Introduction}

Pearl millet [Pennisetum glaucum (L.) R.Br. Syn. Pennisetum americanum (L.) Leeke] is a short duration crop grown mostly in soil with low fertility and rainfall lesser than $400 \mathrm{~mm}$. The crop is cultivated for grains as well as for fodder and provides a low-cost solution to 
combating malnutrition due to micronutrient deficiency. Pearl millet is prone to many diseases however, downy mildew diseases are economically more important. Downy mildew [Sclerospora graminicola (Sacc.) Schroet] is a highly destructive and widespread disease in most pearl millet growing areas of Asia and Africa (Andrews et al., 1985). Sclerospora graminicola (Sacc.) Schroet, incident of downy mildew of pearl millet, is an obligate parasite, belonging to family Peronosporaceae, orders Peronosporales. The epidemic of downy mildew occurred on the first popular pearl millet hybrid HB-3 during 1971 and led to severe grain loss of about 4.6 million MT (Singh, 1995). Gupta and Singh (1996) also reported 57 per cent reduction in the yield besides heavy losses in the fodder yield.

Since Pearl millet is considered as poor man's crop and the disease resistance is the ability to prevent, restrict or retard disease development. In contrast, virulence is the ability (low, moderate or high) of an infectious agent to overcome resistance. Both resistance and virulence are each the combined result of multiple biochemical components (Horsfall and Cowling, 1980). Consequently, any single putative component of resistance needs to be evaluated with many experimental approaches to determine its role in the total defence system. Some of the experimental approaches used to compare biochemical responses in resistant and susceptible plants include: genetically different plants, genetically different pathogens, environmentally altered resistance, ontogenic changes in resistance, induced resistance and induced susceptibility. Biochemical parameters play an important role in resistance or susceptibility in plants against diseases. Plants are equipped with a variety of defence mechanism to protect against the pathogen, some of this are constitutive while others are induced upon the attack of pathogen like accumulation of phenolics or induction of antioxidant and its related enzymatic system (Kandoliya and Vakharia, 2013). Peroxidase has been correlated with disease resistance in many plants. It is an important enzyme in the synthesis of lignin. It is known to catalyze the oxidation of mono- phenols, di- phenols and aromatic amines to the highly toxic quinones in the presence of hydrogen oxides. The enzyme itself has been reported to be toxic to microorganisms. Polyphenol oxidase mainly catalase the oxidation of phenolic substances through a $\mathrm{PPO}-\mathrm{H}_{2} \mathrm{O}_{2}$ system, whose reaction products are highly reactive and toxic to pathogens and are supposed to impart resistance to host (Tayal et al., 1984) whereas Catalase represents one of the primary enzymatic mechanisms employed by aerobic organisms to decompose hydrogen peroxide, a toxic intermediate of oxygen metabolism.

Although, biotrophic pathogens rarely kill their host, the resulting loss of nutrients, increased respiration and decreased photosynthesis seriously reduce growth and yields. It is well known that the disease resistance mechanism is a complex phenomenon and in response to invasion by a disease causing organism, plant produces various kinds of biochemical reactions. Therefore, analysis of biochemicals in selected resistant and susceptible cultivars to downy mildew was carried out. In the present study, biochemical changes in susceptible (7042 S) and resistant (HHB 223) genotypes of pearl millet were estimated at different stages to correlate the disease with various biochemical parameter to combat the pathogen.

\section{Materials and Methods}

Fresh leaf samples of pearl millet genotypes viz., Resistant (HHB 223) and susceptible 7042S sown under sick plot condition of CCS Haryana Agricultural University Hisar (Haryana) were collected from second upper leaf and washed twice with tap water and then 
with milli $Q$ water. Infected and uninfected leaves without midrib were analysed in triplicate for biochemical estimation at 30, 40, 50 and 70 days after sowing (DAS).

Extraction and estimation of total phenols and different types of phenols

Total phenols and different phenols were extracted from leaves using $80 \%$ hot alcohol. Dry powdered sample $(0.1 \mathrm{~g})$ of susceptible and resistant genotype was homogenized with $80 \%$ ethanol (total $10 \mathrm{ml}$ ) and centrifuged at $5000 \mathrm{rpm}$ for 15 minutes, supernatant was taken and final volume was made upto $10 \mathrm{ml}$ with $80 \%$ ethanol. Total phenolic content was estimated by the method of Swain and Hillis (1959) using Folin-Ciocalteau reagent. Orthodihydroxy phenols and flavanols were estimated by the method of Johnson and Schaal (1952) and Balbaa et al., (1974), respectively.

\section{Chlorophyll content and carotenoid}

Chlorophyll content of the leaves was determined by the method of Arnon (1956). One hundred $\mathrm{mg}$ of fresh leaf material from the healthy and diseased leaves was homogenized in $80 \%$ Acetone separately and centrifuged at 10,000 rpm for 10 minutes. The supernatant was kept aside and residue was again extracted with $5 \mathrm{ml} 80 \%$ Acetone till the supernatant became colourless. All the supernatant samples were pooled together and the volume was made to $15 \mathrm{ml}$ with $80 \%$ acetone. The optical density was measured at 450, 645 and $663 \mathrm{~nm}$ against $80 \%$ acetone as blank by using spectrophotometer.

\section{Protein content}

Total nitrogen in the samples was estimated by conventional Micro-Kjeldahl's method. Crude protein content was calculated by multiplying nitrogen content with suitable factor (3.25).
Extraction and estimation of different enzymes

\section{Preparation of extract}

Plant material i.e., roots and leaves separately taken were washed with cold distilled water and dabbed dry with several folds of filter paper. Extraction conditions were standardized with respect to molarity and $\mathrm{pH}$ of buffer to achieve maximum extraction of enzymes in leaves. All the steps of extraction were carried out at $0-4^{\circ} \mathrm{C} .200 \mathrm{mg}$ tissue was macerated in chilled pestle and mortar in the presence of $10 \mathrm{ml} 0.1 \mathrm{M}$ phosphate buffer $(\mathrm{pH}$ 7.5). The homogenate was centrifuged at $10,000 \mathrm{~g}$ for 20 minutes at $4^{\circ} \mathrm{C}$. The supernatant was carefully decanted and used as the crude enzyme preparation.

\section{Enzyme assay}

Peroxidase activity was estimated by the method of Shannon et al., (1966). Catalase activity was determined by the procedure of Sinha (1972). Polyphenol oxidase activity was estimated by the method of Taneja and Sachar (1974). Phenylalanine Ammonia Lyase and Tyrosine Ammonia Lyase activity was estimated by the method of Biehn et al., (1968).

\section{Results and Discussion}

Sugars act as precursor for synthesis of phenolics, phytoalexins, lignin and cellulose which plays an important role in defence mechanism of plants against invading pathogens. Phenolic compounds are plant secondary metabolites that constitute one of the most common and widespread groups of substances in plants. The importance of phenolic compounds in disease resistance has been recognized since long. Phenol content in the form of total phenol, orthodihydroxy phenol and flavanol in leaves of resistant and 
susceptible genotypes of pearl millet is presented in Table 1.

\section{Phenols}

The observations revealed that at 30 DAS higher content of phenols were observed in HHB 223 (9.2 $\mathrm{mg}$ catechol equi./g) in comparison to $4.7 \mathrm{mg}$ catechol equi./g in $7042 \mathrm{~S}$ but with the advancement of disease total phenols decreased in resistant genotype (7.8 mg catechol equi./g) while in susceptible it increased (5.5 mg catechol equi./g) at 40 DAS. At 50 DAS, total phenol increased in resistant (8.6 mg catechol equi./g) as well as in susceptible genotype $(7.1 \mathrm{mg}$ catechol equi./g). At 70 DAS, total phenol content in susceptible genotype was maximum (10.3 mg catechol equi./g) in comparison to resistant genotype (8.0 mg catechol equi./g) (Table 1). The results corroborated the findings of Yadav et al., (1998) that total phenols increased during the early stages of plant growth (30 DAS) but decreased with plant age and increase in infection in highly susceptible and moderately resistant genotypes. Mahatma et al., (2011) also reported that total phenols increased in susceptible genotypes and decreased in resistant genotypes of pearl millet after infection with downy mildew pathogen.

\section{Orthodihydroxy phenols}

The Orthodihydroxy Phenol content was estimated maximum in resistant genotype (1.7 mg catechol equi. /g) in comparison to susceptible genotype (1.0 mg catechol equi./g) at 30 DAS. Further, it decreased in the resistant (1.4 mg catechol equi./g) but remain unchanged in the susceptible genotype at 40 DAS. However, it remained same in the resistant genotype (1.4 mg catechol equi./g) but increased in the susceptible genotype (1.3 mg catechol equi./g) At 50 DAS. But it further increased in resistant genotype $(1.5 \mathrm{mg}$ catechol equi./g) and it remained unchanged
(1.3 mg catechol equi./g) in susceptible at 70 DAS (Table 1). These results are in consistent with the findings of Kumar et al., (2013) who reported that Orthodihydroxy phenols were higher in resistant genotype as compared to susceptible genotypes of chickpea in response to Ascochyta blight attack.

\section{Flavanol}

The higher flavanols were observed in resistant (13 $\mathrm{mg}$ catechol equi./g) in comparison to susceptible genotype $(9.2 \mathrm{mg}$ catechol equi./g) at 30 DAS., whereas tremendous reduction in flavanol content was observed in both the genotypes at 40 DAS. But it remained unchanged in resistant genotype (9.1 mg catechol equi./g) and increased in susceptible genotype $(8.7 \mathrm{mg}$ catechol equi./g) at 50 DAS. From the observation it revealed that with the advancement of the disease flavanols content further decreased in both the genotypes but observed more reduction in susceptible genotype (4.1 mg catechol equi./g). Dhingra et al., (2013) also observed that higher total flavanoid content in moderately resistant genotype as compared to susceptible genotype of cauliflower against Alternaria blight in corroborative to the observations of this experiment.

\section{Total chlorophyll and carotenoids}

The estimation of Total chlorophyll content in leaves at four successive stages of growth and development viz., 30, 40, 50 and 70 DAS revealed that in both genotypes there was reduction in chlorophyll content from 30 to 40 DAS while slight hike observed from 40 to 50 DAS. The total chlorophyll content further decreased at 70 DAS in resistant genotype but in case of susceptible genotype it decreased with the progression of disease at all stages (Table 2). In resistant genotype, carotenoid was more $(1.01 \mathrm{mg} / \mathrm{g})$ in comparison to 
susceptible genotype $(0.56 \mathrm{mg} / \mathrm{g})$ at 30 DAS. At 40 DAS it decreased in both resistant $(0.77$ $\mathrm{mg} / \mathrm{g})$ and susceptible genotype $(0.51 \mathrm{mg} / \mathrm{g})$. There was increase in carotenoid content in resistant genotype at 50 DAS but in susceptible it further decreased $(0.50 \mathrm{mg} / \mathrm{g})$. It further increased to maximum of $1.30 \mathrm{mg} / \mathrm{g}$ in resistant genotype and $0.54 \mathrm{mg} / \mathrm{g}$ in susceptible genotype at 70 DAS. Mahatma et al., (2009) reported that at post-infection stage a significant decrease in chlorophyll and carotenoids content occur in susceptible genotypes however Ghose et al., (2010) reported a drastic reduction of about $53.24 \%$ and $58.04 \%$ in total chlorophyll and carotene respectively in blight infected mulberry leaves.

\section{Total soluble sugars}

The total soluble sugar was observed in healthy (resistant) as well as diseased (susceptible) genotype and the results are presented in Table 3.

The results indicated that total soluble sugars in healthy resistant genotype were higher at each stage of the crop in comparison to susceptible diseased plant. At 30 DAS, resistant genotype exhibited higher level of total soluble sugars (10.64 mg glucose equi./g) whereas in susceptible it was only $2.21 \mathrm{mg}$ glucose equi./g. The depletion of sugars was maximum in resistant genotype in comparison to susceptible genotype with the progression of the disease. Dhingra et al., (2013) reported that moderately resistant genotypes had higher total soluble sugars than the susceptible genotypes against Alternaria blight in cauliflower genotypes. The significant reduction in the total soluble sugar level was observed in all the genotypes after infection.

\section{Proteins}

The observations of Protein content recorded in healthy (resistant) and diseased (susceptible) genotype are presented in Table 4.

The results indicated that at 30 DAS, the protein content was more $(25.20 \%)$ in susceptible genotype in comparison to the resistant genotype (19.78\%). However, protein content increased in both the genotypes i.e. $20.65 \%$ in resistant genotype and $27.30 \%$ in susceptible genotype at 40 DAS. But increased in resistant $(25.03 \%)$ and reduced in susceptible genotype $(20.30 \%)$ at 50 DAS. Further at 70 DAS, it decreased to $21.88 \%$ in resistant genotype while in susceptible genotype the protein content was $19.6 \%$. The present findings corroborated with the reports of Dhingra et al., (2013) that moderately resistant genotypes had higher proteins than the susceptible genotypes against Alternaria blight in cauliflower. The reduction in total proteins was at a higher rate in susceptible ones than the moderately resistant genotypes.

The antioxidant enzyme activities in terms of peroxidase, polyphenol oxidase and catalase are presented in Table 5.

\section{Peroxidase}

The peroxidase activity was lower in healthy resistant genotype (308.20 Change in OD/g) in comparison to diseased susceptible genotype (348.20 Change in OD/g) at 30 DAS. The peroxidase activity increased in susceptible genotype (402.35 Change in OD/g) but decreased in resistant genotype (198.30 Change in $\mathrm{OD} / \mathrm{g}$ ) at $40 \mathrm{DAS}$. In resistant genotype peroxidase activity increased from 50 to 70 DAS (304 to 433 Change in OD/g) but in susceptible it was 252.40 Change in $\mathrm{OD} / \mathrm{g}$ at $50 \mathrm{DAS}$ and 308.20 Change in OD/g at 70 DAS. In comparison to the observation of the present studies, Mahatma et al., (2009) found that POX activity was found to be lower in resistant genotypes than the susceptible genotypes of pearl millet at pre-infection stage. 
Table.1 Phenolic content in leaves of downy mildew resistant (R) HHB 223 and susceptible (S) $7042 \mathrm{~S}$ pearl millet genotypes at different stages of growth

\begin{tabular}{|c|c|c|c|c|}
\hline $\begin{array}{c}\text { Days after } \\
\text { sowing (DAS) }\end{array}$ & Genotype & $\begin{array}{l}\text { Total phenolic content } \\
\text { (mg catechol equi./g) }\end{array}$ & $\begin{array}{l}\text { Orthodihydroxy phenol } \\
\text { (mg catechol equi./g) }\end{array}$ & $\begin{array}{c}\text { Flavanol } \\
\text { (mg catechol equi./g) }\end{array}$ \\
\hline \multirow[t]{2}{*}{30} & HHB 223 (R) & 9.2 & 1.7 & 13.0 \\
\hline & $7042 \mathrm{~S}(\mathrm{~S})$ & 4.7 & 1.0 & 9.2 \\
\hline \multirow[t]{2}{*}{40} & HHB 223 (R) & 7.8 & 1.4 & 9.1 \\
\hline & $7042 \mathrm{~S}(\mathrm{~S})$ & 5.5 & 1.0 & 6.6 \\
\hline \multirow[t]{2}{*}{50} & HHB 223 (R) & 8.6 & 1.4 & 9.1 \\
\hline & 7042 S (S) & 7.1 & 1.3 & 8.7 \\
\hline \multirow[t]{2}{*}{70} & HHB $223(\mathrm{R})$ & 8.0 & 1.5 & 8.3 \\
\hline & $7042 \mathrm{~S}(\mathrm{~S})$ & 10.3 & 1.3 & 4.1 \\
\hline \multicolumn{2}{|c|}{ CD at $5 \%$} & $\begin{aligned} D & =0.6 \\
G & =0.4 \\
D \times G & =0.9\end{aligned}$ & $\begin{array}{c}D=0.1 \\
G=0.1 \\
D \times G=0.1\end{array}$ & $\begin{array}{l}D=0.857 \\
G=0.5 \\
D \times G=1.1\end{array}$ \\
\hline
\end{tabular}

Where

D - Days after sowing $\quad \mathrm{G}-$ Genotype

Table.2 Chlorophyll content in leaves of downy mildew resistant (R) HHB 223 and susceptible (S) $7042 \mathrm{~S}$ pearl millet genotypes at different stages of growth

\begin{tabular}{|c|c|c|c|}
\hline $\begin{array}{c}\text { Days after sowing } \\
\text { (DAS) }\end{array}$ & Genotype & $\begin{array}{c}\text { Total chlorophyll } \\
\text { (mg/g) }\end{array}$ & $\begin{array}{c}\text { Carotenoids } \\
(\mathrm{mg} / \mathrm{g})\end{array}$ \\
\hline \multirow[t]{2}{*}{30} & HHB 223 (R) & 14.20 & 1.01 \\
\hline & $7042 S(S)$ & 6.65 & 0.56 \\
\hline \multirow[t]{2}{*}{40} & HHB $223(\mathrm{R})$ & 12.16 & 0.77 \\
\hline & $7042 \mathrm{~S}(\mathrm{~S})$ & 6.44 & 0.51 \\
\hline \multirow{2}{*}{50} & HHB 223 (R) & 12.76 & 0.91 \\
\hline & $7042 \mathrm{~S}(\mathrm{~S})$ & 5.72 & 0.50 \\
\hline \multirow[t]{2}{*}{70} & HHB 223 (R) & 11.08 & 1.30 \\
\hline & $7042 \mathrm{~S}(\mathrm{~S})$ & 4.27 & 0.54 \\
\hline
\end{tabular}

Table.3 Total soluble sugars in leaves of resistant (R) HHB 223 and susceptible (S) 7042 S pearl millet genotypes at different stages of growth

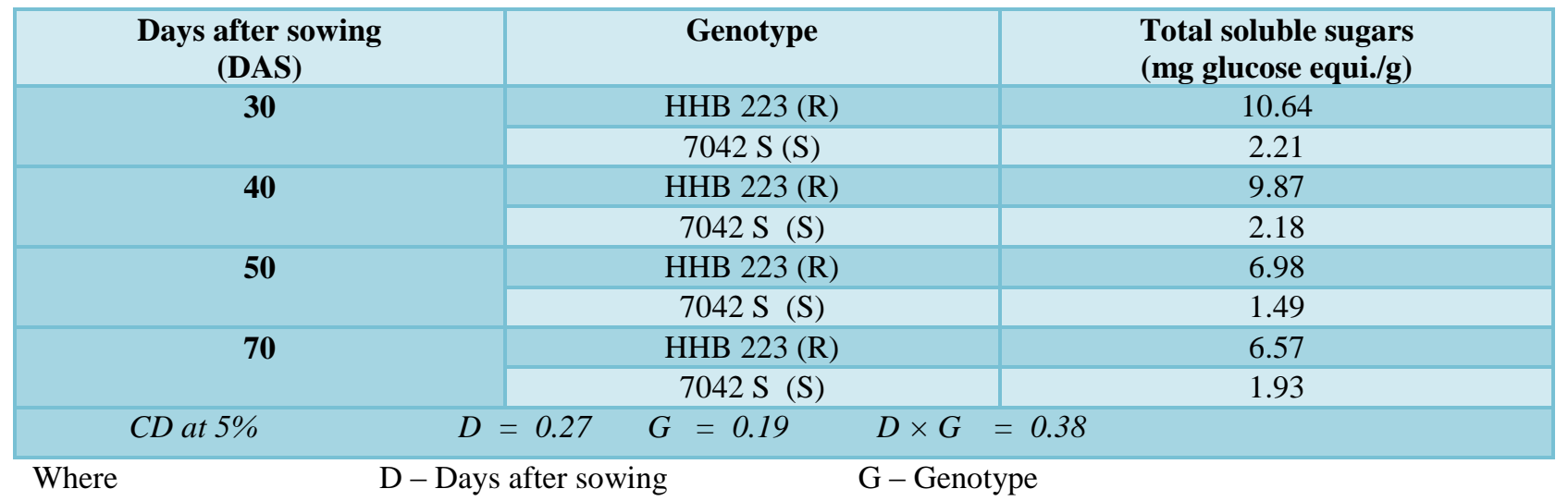


Table.4 Proteins content in leaves of downy mildew resistant (R) HHB 223 and susceptible (S) $7042 \mathrm{~S}$ pearl millet genotypes at different stages of growth

\begin{tabular}{|c|c|c|}
\hline Days after sowing (DAS) & Genotype & Protein (\%) \\
\hline \multirow[t]{2}{*}{30} & HHB $223(\mathrm{R})$ & 19.78 \\
\hline & $7042 \mathrm{~S}(\mathrm{~S})$ & 25.20 \\
\hline \multirow[t]{2}{*}{40} & HHB $223(\mathrm{R})$ & 20.65 \\
\hline & $7042 \mathrm{~S}(\mathrm{~S})$ & 27.30 \\
\hline \multirow[t]{2}{*}{50} & HHB $223(\mathrm{R})$ & 25.03 \\
\hline & $7042 S(S)$ & 20.30 \\
\hline \multirow[t]{2}{*}{70} & HHB $223(\mathrm{R})$ & 21.88 \\
\hline & $7042 \mathrm{~S}(\mathrm{~S})$ & 19.60 \\
\hline$D=0.34$ & $D \times G=0.47$ & \\
\hline
\end{tabular}

Table.5 Antioxidant enzyme activities in leaves of resistant (R) HHB 223 and susceptible (S) $7042 \mathrm{~S}$ pearl millet genotypes at different stages of growth

\begin{tabular}{|c|c|c|c|c|}
\hline $\begin{array}{c}\text { Days after } \\
\text { sowing (DAS) }\end{array}$ & Genotype & $\begin{array}{c}\text { Peroxidase } \\
\text { (Change in OD/g) }\end{array}$ & $\begin{array}{l}\text { Polyphenol oxidase } \\
\text { (Change in OD/g) }\end{array}$ & $\begin{array}{c}\text { Catalase } \\
\text { (Change in OD/g) }\end{array}$ \\
\hline \multirow[t]{2}{*}{30} & HHB 223 (R) & 308.20 & 2.02 & 11.87 \\
\hline & $7042 \mathrm{~S}(\mathrm{~S})$ & 348.20 & 2.08 & 15.87 \\
\hline \multirow[t]{2}{*}{40} & HHB 223 (R) & 198.30 & 1.72 & 9.62 \\
\hline & $7042 \mathrm{~S}(\mathrm{~S})$ & 402.35 & 1.92 & 12.25 \\
\hline \multirow[t]{2}{*}{50} & HHB 223 (R) & 304.05 & 1.74 & 18.37 \\
\hline & $7042 \mathrm{~S}(\mathrm{~S})$ & 252.40 & 1.89 & 14.50 \\
\hline \multirow[t]{2}{*}{70} & HHB 223 (R) & 433.95 & 2.15 & 14.90 \\
\hline & $7042 \mathrm{~S}(\mathrm{~S})$ & 308.20 & 1.95 & 9.40 \\
\hline \multicolumn{2}{|c|}{$C D$ at $5 \%$} & $\begin{array}{c}D=18.42 \\
G=13.03 \\
D \times G=26.05\end{array}$ & $\begin{array}{c}D=0.04 \\
G=0.03 \\
D \times G=0.05\end{array}$ & $\begin{array}{c}D=1.05 \\
G=N / A \\
D \times G=1.49\end{array}$ \\
\hline
\end{tabular}

Where

$$
\text { D - Days after sowing } \quad G-\text { Genotype }
$$

Table.6 Change in enzyme activities in leaves of downy mildew resistant (R) HHB 223 and susceptible (S) $7042 \mathrm{~S}$ pearl millet genotypes at different stages of growth

\begin{tabular}{|c|c|c|c|}
\hline Days after sowing (DAS) & Genotype & PAL (Change in OD/g) & TAL (Change in OD/g) \\
\hline \multirow[t]{2}{*}{30} & HНB 223 (R) & 0.72 & Traces \\
\hline & $7042 \mathrm{~S}(\mathrm{~S})$ & 2.16 & Traces \\
\hline \multirow[t]{2}{*}{40} & HHB 223 (R) & 1.95 & Traces \\
\hline & $7042 \mathrm{~S}(\mathrm{~S})$ & 3.01 & Traces \\
\hline \multirow[t]{2}{*}{50} & HНB $223(\mathrm{R})$ & 1.76 & Traces \\
\hline & $7042 \mathrm{~S}(\mathrm{~S})$ & 4.07 & Traces \\
\hline \multirow[t]{2}{*}{70} & HНB 223 (R) & 1.52 & Traces \\
\hline & $7042 \mathrm{~S}(\mathrm{~S})$ & \multicolumn{2}{|l|}{$G=053$} \\
\hline CD at $5 \%$ & $D=0.74$ & $G=0.53$ & \\
\hline
\end{tabular}




\section{Polyphenol oxidase}

The polyphenol oxidase activity was almost similar (2.02 Change in OD/g) in resistant genotype and susceptible genotype (2.08 Change in $\mathrm{OD} / \mathrm{g}$ ) at $30 \mathrm{DAS}$. At $40 \mathrm{DAS}$, however, the activity decreased in resistant (1.72 Change in OD/g) as well in susceptible genotype (1.92 Change in OD/g) but there was increase in PPO activity from 50 to 70 DAS in resistant genotype $(1.74-2.15$ Change in $\mathrm{OD} / \mathrm{g}$ ) and decrease in susceptible (1.89 Change in OD/g) at 50 DAS and then increased (1.95 Change in OD/g) at $70 \mathrm{DAS}$.

\section{Catalase}

The catalase activity was higher in susceptible (15.87 Change in $\mathrm{OD} / \mathrm{g}$ ) in comparison to resistant genotype (11.87 Change in OD/g) at 30 DAS but decreased in both the genotypes at 40 DAS, and reduction was more in resistant genotype (9.62 Change in $\mathrm{OD} / \mathrm{g}$ ) in comparison to susceptible (12.25 Change in $\mathrm{OD} / \mathrm{g}$ ). The resistant genotype had higher catalase activity (18.37 Change in OD/g) in comparison to susceptible genotype (14.50 Change in $\mathrm{OD} / \mathrm{g}$ ) at $50 \mathrm{DAS}$. It further reduced in resistant (14.90 Change in OD/g) as well as susceptible genotype (9.40 Change in $\mathrm{OD} / \mathrm{g}$ ) at 70 DAS (Table 5)

\section{Phenylalanine Ammonia Lyase (PAL) and} Tyrosine Ammonia Lyase (TAL)

The observations revealed that PAL activity in the leaves of resistant genotypes was lower (0.72 Change in OD/g) in comparison to the susceptible genotype (2.16 Change in OD/g) at 30 DAS (Table 6).

The PAL activity increased to 3.01 Change in $\mathrm{OD} / \mathrm{g}$ in susceptible genotype and 1.95 Change in $\mathrm{OD} / \mathrm{g}$ in resistant genotype at 40 DAS., but decreased in resistant (1.76 Change in $\mathrm{OD} / \mathrm{g}$ ) and increased in susceptible genotype (4.07 Change in OD/g at $50 \mathrm{DAS}$ ). PAL activity was maximum in susceptible genotype (7.93 Change in $\mathrm{OD} / \mathrm{g})$ in comparison to resistant genotype (1.52 Change in OD/g) at 70 DAS. TAL activity was observed in traces in both the genotypes at all the stages. Geetha et al., (2005) reported elevation in PAL activity in resistant host cultivar that decreased in susceptible cultivars following downy mildew infection.

In conclusion, disease resistance in plants is associated with the activation of a wide variety of defense responses, which serve to prevent pathogen infection. These mechanisms include, pre-existing physical and chemical barriers, as well as inducible defense responses in the form of induction of defense related enzymes, that become activated upon pathogen infection. The presence or activities of enzymes can be used as biochemical markers for the degree of resistance and these defense related enzymes play a prominent role, either directly or indirectly in resistant genotypes. Through the present investigations it was found that various metabolites like protein content, total soluble sugar, total phenol, chlorophyll content as well as antioxidant enzymes like peroxidase, polyphenol oxidase and catalase be explored to amongst the various pearl millet entries for quick resistance to downy mildew which will be most economical for the end user i.e. farmers..

\section{References}

Andrews D.J., King S.B., Witcomb J.R., Singh S.D., Rai K.N., Thakur R.P., Talukdar B.S., Chavan S.B. and Singh P. 1985. Breeding for disease resistance and yield in pearl millet. Field Crops Research. 11: 241-58.

Arnon D.B. 1956. Chlorophyll absorption spectrum and quantitative determination. Biochimica et Biophysica Acta 20: 449-61.

Balbaa S.I., Zaki A.Y. and Glsharmy A.M. 1974. Total flavanol and rutin content of different organs of Soohora japonica $L$. Journal of Association of official Analytical Chemists 57: 752-55. 
Biehn W.L., Kue J. and Williams E.B. 1968. Accumulation of phenols in resistant plant-fungi interaction. Phytopathology 58: 1255-60.

Dhingra M., Arora N. and Asujla I.S. 2013. Biochemical characteristics imparting resistance against Alternaria blight in cauliflower genotypes. Agricultural Science Digest 33(2): 92-7.

Geetha N.P., Amruthesh K.N., Sharathchandra R.G. and Shetty H.S. 2005. Resistance to downy mildew in pearl millet is associated with increased phenylalanine ammonia lyase activity. Functional Plant Biology 32: 267-75.

Ghose L., Neela F.A., Chakravorty T.C., Ali M.R. and Alam M.S. 2010. Incidence of leaf blight disease of mulberry plant and assessment of changes in amino acids and photosynthetic pigments of infected leaf. Plant Pathology Journal 95: 140-3.

Gupta S.K. and Singh D. 1996. Studies on the influence of downy mildew infection on yield and yield- contributing plant characters of pearl millet in India. International Journal of Pest Management 42: 89 - 93.

Horsfall, J.G., and Cowling, E.B. 1980. Plant Disease: An Advanced Treatise. Vol V. How Plant Defend Themselves. New York: Academic. 534 pp.

Johnson G. and Schaal L.A. 1952. Relation of chorogenic acid to scab resistance in potatoes. Science 115: 627-9.

Kandoliya U.K. and Vakharia D.N. 2013. Antagonistic effect of Pseudomonas fluorescens against Fusarium oxysporum f.sp. Ciceri causing wilt in chickpea. Legume Research 36(6): 56970.

Kumar R., Appunu C., Mahadeviah C., Sreenivasa V., Waldia R.S., Meena M.R. and Chhabra M.L. 2013. Impact of Aschochyta blight disease on the expression of biochemical compounds in chickpea. Legume Research. 36(3): 268-70.

Mahatma M.K.., Bhatnagar R., Dhandhukia P. and Thakkar V.R. 2009. Variation in metabolites constituent in leaves of downy mildew resistant and susceptible genotypes of pearl millet. Physiology and Molecular Biology of Plants 15(3): 249-55.

Mahatma M.K., Bhatnagar R., Mittal G.K. and Mahatma L. 2011. Phenol metabolism in downy mildew resistant and susceptible genotypes of pearl millet. Archives of Phytopathology and Plant Protection 44(7): 623-36.

Shannon L.M., Key E. and Law J.Y. 1966. Peroxidase isoenzymes from horse reddish roots: isolation and physical properties. Journal of Biological Chemistry 241: 2166-72.

Sinha A.K. 1972. Colorimetric assay of catalase. Annals of Biochemistry 47:389-94.

Singh S.D. 1995. Downy mildew of pearl millet. Plant Disease 79: 545-50.

Swain, T. and Hillis, W.E. 1959. The phenolic constituents of Prunus domestica: the quantitative analysis of phenolic constituents. Journal of the Science of Food and Agriculture 10: 63-68.

Taneja S.R. and Sachar R.C. 1974. Induction of polyphenol oxidase in germinating wheat seeds. Phytochemistry 13: 2695702.

Tayal, M.S., Agarwal, M.L., Goel, A.K. and Kumar, S. 1984. Starch, IAA, amino acids and oxidative enzymes in leaves of Phoenix sylvestris infected by Graphiola phoenicis. Indian Phytopathology 37: 146-148.

Yadav N.K., Thakur D.P. and Rathi A.S. 1998. Biochemical changes in pearl millet leaves due to downy mildew infection. Haryana Agricultural University Journal of Research 28: 81-5.

\section{How to cite this article:}

Pooja Sangwan, Kushal Raj, L.K. Chugh, Annu and Annie Khanna 2018. Attribution of Biochemical Characters in Downy Mildew Resistant and Susceptible Hybrids of Pearl Millet. Int.J.Curr.Microbiol.App.Sci. 7(05): 2590-2598. doi: https://doi.org/10.20546/ijcmas.2018.705.299 